\title{
DIVISÃO SEXUAL DO TRABALHO: AS CONTRADIÇÕES DOS DISCURSOS ENTRE CAPITAL E TRABALHO NO INTERIOR DA FÁBRICA
}

\author{
THE SEXUAL DIVISION OF LABOR: CONTRADICTIONS IN THE \\ DISCOURSES OF CAPITAL AND LABOR WITHIN THE FACTORY
}

\begin{abstract}
Vera Regina Resnauer Taques da Silva Dias ${ }^{1}$ Marília Gomes de Carvalho ${ }^{2}$ Nilson Marcos Dias Garcia ${ }^{3}$

RESUMO

Investigou-se, com esta pesquisa como ocorre a divisão sexual do trabalho no capitalismo contemporâneo a partir de sua constituição histórica. Examinou-se esses aspectos relacionando-os com as formas de organização do trabalho fabril em uma indústria de eletrodomésticos, em Curitiba. A pesquisa foi qualitativa, por meio de entrevistas realizadas com trabalhadores(as) da área de produção e com uma profissional da área de $\mathrm{RH}$. Os objetivos foram: conhecer como a empresa emprega o trabalho feminino no setor fabril; qual a percepção que trabalhadores/as têm das características do trabalho que realizam. Para tanto, abordou-se as relações de gênero np âmbito da crise do trabalho abstrato, decorrente da reestruturação da produção capitalista. Constatou-se a existência de um grau de divisão sexual do trabalho que coloca a mulher em condição subalterna em relação ao homem. Em muitos casos as funções são as mesmas, porém os cargos e a remuneração são diferentes, com menor prestígio e menor valor.
\end{abstract}

Palavras-chave: Desenvolvimento tecnológico; reestruturação produtiva; relações de gênero.

\begin{abstract}
Through this research we have investigated how the division of labor unfolds within contemporary capitalism, taking its historical constitution as our point of departure. These questions have been examined and then related to forms of work organization in an electro-domestics factory in the city of Curitiba, through qualitative research that carried out interviews with production workers (women and men) and with one (female) professional in the area of Human Resources. Our goals were to discover how the firm uses female work in the production sector and how workers perceive the labor they carry out. For these purposes, we look at gender relations within the context of the crisis of abstract labor that comes as consequence of the restructuring of capitalist production. We confirm the existence of a high degree of sexual division of labor that situates women in a subaltern condition in relation to men. In many cases functions are the same, yet positions and remuneration are unequal, affording womenlesser prestige and lower wages.
\end{abstract}

Keywords: Technological development; restructuring of production; gender gender relations.

1 Graduada em Pedagogia e Mestre em Tecnologia pela UTFPR. E-mail: verareginadias@gmail.com

2 Graduada em Antropologia/Sociologia e Pós-doutora em Multiculturalismo pela U. Compiègnie da França. Professora do PPGTE/UTFPR, pesquisadora e coordenadora do GeTec. E-mail: mariliagdecarvalho@gmail.com

3 Graduado em Física e Doutor em Educação pela USP. Professor do PPGTE/UTFPR. E-mail: nilson@utfpr.edu.br 


\section{INTRODUÇÃO}

A elaboração deste artigo está associada à realização de estudos no Grupo de Estudos e Pesquisas sobre Relações de Gênero e Tecnologia GeTec, da Universidade Tecnológica Federal do Paraná, e da pesquisa realizada para desenvolvimento da dissertação de Mestrado em Tecnologia, do Programa de Pós-Graduação Tecnologia, da referida Universidade, em uma indústria de eletrodomésticos, em Curitiba.

Tomando por base as mudanças recentes que vêm atingindo os processos de trabalho e a organização da produção, no bojo da reestruturação produtiva, caracterizadas pelo novo padrão de acumulação de capital de base flexível e de maior competitividade, este estudo tomou como objeto de investigação a divisão sexual do trabalho, em uma indústria de eletrodomésticos, na região de Curitiba, compreendendo uma investigação empírica sobre a realidade concreta das condições de trabalho. Para isso foram desenvolvidas entrevistas com 14 trabalhadores e trabalhadoras operacionais e 1 da área de Recursos Humanos da referida indústria.

A entidade empresarial na qual a pesquisa foi realizada, aqui denominada Empresa, é uma indústria transnacional, considerada dentre as maiores do mundo no ramo de fabricação e montagens de eletrodomésticos. No período em que a pesquisa foi realizada, em agosto de 2005, contava com 1178 funcionários, sendo 738 homens e 440 mulheres. As entrevistas foram concebidas de modo a dar a caracterização das condições socioeconômicas do corpo de funcionários na visão da empresa e identificar a percepção que os trabalhadores e trabalhadoras têm sobre a sua condição no processo produtivo.

Questionou-se até que ponto a flexibilidade produtiva que vem construindo um novo desenho ocupacional, diferente da divisão tayloristafordista, propicia condições para uma melhor inserção da mulher nas atividades produtivas.

Partindo dessa problematização a pesquisa tem como objetivos investigar como a Empresa emprega o trabalho feminino e qual a noção que expressa acerca dele, bem como a percepção que trabalhadores e trabalhadoras têm das características do trabalho que realizam, em que condições o executam, envolvendo a percepção que têm de si, enquanto trabalhadores.

A investigação realizada com o grupo de trabalhadores e trabalhadoras e a representante empresarial caracteriza-se enquanto pesquisa qualitativa, de acordo com CHIZZOTTI (2000, p. 78), abrigando "correntes de pesquisa muito diferentes" as quais se fundamentam "em alguns pressupostos contrários ao modelo experimental" e adotando "métodos e técnicas de pesquisa diferentes dos estudos experimentais". A pesquisa qualitativa constitui-se a partir de um conjunto de fundamentos e técnicas aplicáveis nos estudos do comportamento humano e social realizados pelas Ciências Humanas.

O artigo está constituído por três partes. Na primeira, consta a caracterização dos atores da pesquisa - trabalhadores e trabalhadores da área operacional e a representante empresarial, da área de Recursos Humanos. A segunda parte apresenta as relações de gênero na Empresa pesquisada, 
mostrando a visão da força de trabalho feminina na concepção da área de $\mathrm{RH}$, patronal, bem como a identidade dos trabalhadores e trabalhadoras da área operacional. Na última parte são apresentadas as Considerações Finais do estudo, contendo as principais contribuições por ele produzidas.

\section{OS ENTREVISTADOS - ATORES DA PESQUISA}

\subsection{CARACTERIZAÇÃO DA REPRESENTANTE DA EMPRESA}

A responsável pelo fornecimento das informações e respondente da entrevista, designada pela própria Empresa, trabalha na área de Recursos Humanos, é do sexo feminino, tem 23 anos, solteira, formada em Psicologia e ocupa o cargo de Analista de Recursos Humanos. Trabalha na Empresa há 3 anos, na qual iniciou como estagiária na mesma área. O fato de ser ela do sexo feminino não significa que a pesquisa tenha sido concebida para saber a opinião da mulher, mas da representação da Empresa que, por acaso, a Diretoria destacou uma mulher.

\subsection{CARACTERIZAÇÃO DO GRUPO DE TRABALHADORES(AS) QUE CONSTITUIIRAM O UNIVERSO DA PESQUISA}

O grupo que constituiu os atores da pesquisa é caracterizado segundo a TABELA 1, abaixo:

\section{TABELA 1 - CARACTERIZAÇÃO DOS TRABALHADORES ENTREVISTADOS}

\begin{tabular}{|c|c|c|c|c|c|c|c|c|c|}
\hline Função & 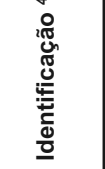 & 齐 & $\begin{array}{l}\frac{0}{0} \\
\frac{\pi}{0}\end{array}$ & $\begin{array}{c}\text { Estado } \\
\text { civil }\end{array}$ & 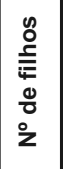 & $\begin{array}{l}\text { Turno de } \\
\text { trabalho }\end{array}$ & 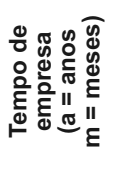 & Escolaridade & Setor \\
\hline $\begin{array}{l}\text { Auxiliar de } \\
\text { produção }\end{array}$ & Alberto & M & 27 & Solteiro & $\begin{array}{l}\text { Não } \\
\text { tem }\end{array}$ & $14 \mathrm{~h}$ às $22 \mathrm{~h}$ & $9 m$ & Fundamental & Injeção \\
\hline $\begin{array}{l}\text { Auxiliar de } \\
\text { produção }\end{array}$ & André & M & 33 & Casado & 3 & $14 \mathrm{~h}$ às $22 \mathrm{~h}$ & $4 a$ & Médio & Injeção \\
\hline $\begin{array}{l}\text { Auxiliar de } \\
\text { produção }\end{array}$ & Aurora & $\mathrm{F}$ & 38 & Casada & 4 & $6 \mathrm{~h}$ às $14 \mathrm{~h}$ & $5 a$ & Fundamental & Impressão \\
\hline $\begin{array}{l}\text { Auxiliar de } \\
\text { produção }\end{array}$ & Adriana & $\mathrm{F}$ & 36 & Casada & 2 & $6 \mathrm{~h}$ às $14 \mathrm{~h}$ & $2 a$ & Fundamental & Impressão \\
\hline
\end{tabular}

4 Todos os verdadeiros nomes dos entrevistados e entrevistadas foram ocultados, sendo substituídos pelos que constam na TABELA 1, atribuídos de modo fictício, como forma de preservação de suas identidades. 


\begin{tabular}{|c|c|c|c|c|c|c|c|c|c|}
\hline Função & 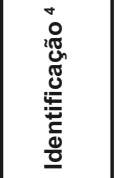 & $\begin{array}{l}\text { வ } \\
\text { હ }\end{array}$ & $\begin{array}{l}\frac{0}{0} \\
\frac{\pi}{0}\end{array}$ & $\begin{array}{c}\text { Estado } \\
\text { civil }\end{array}$ & 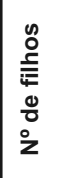 & $\begin{array}{l}\text { Turno de } \\
\text { trabalho }\end{array}$ & 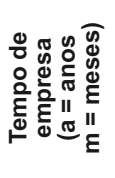 & Escolaridade & Setor \\
\hline $\begin{array}{l}\text { Auxiliar de } \\
\text { produção }\end{array}$ & Arabela & $\mathrm{F}$ & 25 & Casada & 2 & $14 \mathrm{~h}$ às $22 \mathrm{~h}$ & $8 m$ & Fundamental & Injeção \\
\hline $\begin{array}{l}\text { Auxiliar de } \\
\text { produção }\end{array}$ & Ana & $\mathrm{F}$ & 28 & Casada & 2 & $6 h$ às $14 h$ & $3 a$ & Médio & Injeção \\
\hline $\begin{array}{l}\text { Auxiliar de } \\
\text { produção }\end{array}$ & Andréia & $\mathrm{F}$ & 23 & Casada & $\begin{array}{l}\text { Não } \\
\text { tem }\end{array}$ & $22 h$ às $6 h$ & $2 a$ & Fundamental & Impressão \\
\hline $\begin{array}{l}\text { Auxiliar de } \\
\text { produção }\end{array}$ & Amália & $\mathrm{F}$ & 23 & Casada & 1 & $6 h$ às $14 h$ & $1 \mathrm{a} 2 \mathrm{~m}$ & Fundamental & Injeção \\
\hline $\begin{array}{c}\text { Auxiliar de } \\
\text { produção }\end{array}$ & Augusta & $\mathrm{F}$ & 28 & Casada & 2 & $6 h$ às $14 h$ & $2 a$ & Fundamental & Injeção \\
\hline $\begin{array}{l}\text { Operador } \\
\text { de máquina }\end{array}$ & Otacílio & $M$ & 29 & Casado & 2 & $6 h$ às $14 h$ & $4 a$ & Médio & Impressão \\
\hline $\begin{array}{l}\text { Operador } \\
\text { de máquina }\end{array}$ & Odilon & M & 31 & Casado & 3 & $22 \mathrm{~h}$ às $6 \mathrm{~h}$ & 3a & Médio & Impressão \\
\hline $\begin{array}{l}\text { Operador } \\
\text { de máquina }\end{array}$ & Oto & M & 28 & Casado & 3 & $6 h$ às $14 h$ & $5 a$ & Médio & Injeção \\
\hline $\begin{array}{l}\text { Operador } \\
\text { de máquina }\end{array}$ & Oberdan & $M$ & 31 & Casado & 4 & $22 \mathrm{~h}$ às $6 \mathrm{~h}$ & $4 a$ & Médio & Injeção \\
\hline $\begin{array}{l}\text { Supervisor } \\
\text { de produção }\end{array}$ & Sandro & M & 36 & Viúvo & 2 & $14 \mathrm{~h}$ às $22 \mathrm{~h}$ & $5 a$ & Médio & Injeção \\
\hline
\end{tabular}

\section{AS RELAÇÕES DE GÊNERO NA EMPRESA PESQUISADA}

\subsection{A FORÇA DE TRABALHO FEMININA NA VISÃO DA ÁREA DE RECURSOS HUMANOS DA EMPRESA}

Respondendo à questão relacionada ao interesse empresarial pela força de trabalho feminina, de importância deste estudo, a entrevistada da área de RH da Empresa respondeu que "os interesses empresariais pelo emprego do trabalho feminino são contraditórios", fazendo com que a instituição relute na contratação de mulheres.

Analisando os conteúdos desses aspectos "contraditórios" contidos nas afirmações da respondente pelo RH da Empresa, pode-se desdobrá-los em dois campos: "negativos e positivos", segundo os interesses empresariais. Esses dois pólos foram elencados pela entrevistada.

Os "aspectos negativos", ou seja, aquilo que em tese geraria dificuldades à rotina do trabalho, às metas na produtividade e ao padrão de acumulação de capital pela empresa, podem ser identificados por dois ângulos. Um, sobre a condição biológica, envolvendo a gravidez da mulher na procriação humana, e 
outro, relacionado à condição da mulher socialmente determinada, segundo os padrões predominantes de sua subjugação na relação de gênero no casal fora do ambiente de trabalho.

Dentre os fatores de dimensão biológica, apontados pela Empresa, que fazem com que a mesma relute na contratação da mulher estão a "gravidez" e a "licença-maternidade ${ }^{5}$ ". Pois, segundo a entrevistada do $\mathrm{RH}$, que é mulher, esses fatores contribuiriam "para o absenteísmo", compreendido como falta de assiduidade ao trabalho.

A perpetuação da espécie, cuja gravidez não pode ser transferida para o homem, torna-se, assim, um castigo para a mulher, de acordo com essa manifestação da representante do capital. Nesse caso, a condição biológica da mulher torna-a um ser social de segunda opção no momento de concorrer a um emprego numa empresa. Da mesma forma, o direito social conquistado com a licença-maternidade tornou-se uma ameaça e um fator de exclusão da mulher no mercado de trabalho. Ou seja, aquilo que é humano, que é biológico, que é direito adquirido, torna-se causa do "absenteísmo".

Dentre os fatores de ordem social apontados pela Empresa, relacionados com aqueles que tornam a mulher "muito complicada" - como relatou a entrevistada do $\mathrm{RH}$ - estão, "em primeiro lugar", "o cuidado e a preocupação com os filhos" e, ainda, a preocupação "com os maridos, com os companheiros e com o lar". Esses são, de fato, componentes de ordem social que remetem às relações de gênero no trabalho extra-empresarial, atingindo as esferas do cotidiano e da família, mas que se relacionam direta ou indiretamente com a possibilidade de inserção, ou não, da mulher no mercado de trabalho, tal como afirmou Hirata:

(...) as relações homens-mulheres e a atribuição de um certo número de trabalhos exclusivamente às mães limitaram a possibilidade de aparecimento de um comportamento indiferenciado dos membros da família como simples "força de trabalho". Esse problema é reforçado pelo fato de os empregadores também verem as mulheres como as responsáveis pela supervisão da vida familiar. Isso tem como conseqüência uma discriminação, por parte da empresa, das mulheres casadas e uma nítida preferência pelas mulheres solteiras sem filhos e, portanto, sem "família pela qual se responsabilizar" (grifos da autora) (HIRATA, 2002, p. 194).

A relação entre a divisão sexual do trabalho no âmbito familiar e a forma de perceber as condições das mulheres trabalhadoras, segundo a Empresa, está em que "o turno de trabalho do marido é intocável". "É no horário de trabalho delas" - mulheres - "que levam os filhos ao médico e que também muitas vezes resolvem os problemas de casa e dos maridos", afirmou a entrevistada, respondendo pela área de $\mathrm{RH}$.

O campo que caracterizaria os "fatores positivos", que, portanto, favoreceria a contratação e o emprego da força de trabalho feminina pela

5 A licença maternidade é um direito assegurado na Constituição Federal, em 1988, cujo Art. $7^{\circ}$, XVIII, garante "licença à gestante, sem prejuízo do emprego e do salário, com a duração de cento e vinte dias" (BRASIL, 1988, p. 13). 
Empresa, pode ser definido como de natureza social, obedecendo a uma dimensão de ordem comportamental da mulher nas relações de trabalho. A entrevistada do $\mathrm{RH}$ afirma, a partir dos processos de trabalho da Empresa, que "a mulher é muito mais caprichosa e dedicada que o homem". A representante empresarial evidencia isso a partir da relação que a mulher estabelece com o posto de trabalho e com a obediência às ordens. Ela afirmou que "elas" - as mulheres - "respeitam mais os horários e as normas de segurança" e "acatam melhor as orientações passadas". (...) "Nas questões de negociações salariais elas também não argumentam muito". O grau de adesão aos objetivos da empresa e à baixa resistência das mulheres trabalhadoras à exploração da sua força de trabalho pelo capital (a Empresa), fica evidente quando a representante da área de $\mathrm{RH}$, respondente desta pesquisa, afirma: "Nas festas de final de ano que realizamos para os funcionários percebemos o orgulho que elas têm em mostrar aos filhos e à família o lugar em que trabalham. Tiram fotografias e fazem questão de vir apresentá-los à gente".

As afirmações da representante empresarial confirmam impressões do senso comum, isto é, da ideologia dominante em nossa sociedade acerca da conduta feminina como de "ser mais caprichosa, obediente, menos contestadora, etc.". Essa ideologia, no entanto, predomina entre as mulheres em que há um alto grau de conformismo que acaba sendo útil à hierarquização social imposta pelo capital. Não se trata de atributos naturais e, sim, socialmente construídos. Essa visão dicotômica que associa posturas, comportamentos, ao sexo, reproduz uma noção biologizante que vem sendo superada pela perspectiva relacional do gênero.

Trata-se de um grande paradoxo. Por um lado, a condição de subjugação da mulher fora da empresa é um fator que a desqualifica na hora de disputar um emprego com o homem, porque ela assume um conjunto de responsabilidades no cotidiano familiar que geraria um "absenteísmo" no trabalho empresarial, condição em que levaria a empresa a dar preferência por "mulheres solteiras, sem filhos e sem família pela qual se responsabilizar", tal qual buscou-se a afirmação de HIRATA (2002) anteriormente, ou por homens em vez de mulheres. Por outro, a Empresa aponta como atributo importante das mulheres trabalhadoras um conjunto de atitudes de natureza subjugada, reduzindo a condição da mulher enquanto sujeito.

Segundo a representante do $\mathrm{RH}$, as mulheres "são respeitadas" na fábrica. Ela afirmou que o número de mulheres já foi bem menor que o que existe atualmente: "hoje tem muitas e são essenciais". Para ela a preferência pela força de trabalho feminina na Empresa está situada nas áreas de "acabamentos, embalagens e controle de qualidade", mas que "são também ótimas auxiliares de produção".

Estudos realizados a partir da década de 1990, sobre os processos da reestruturação produtiva, como os de HIRATA (1998 e 2002), CUNHA (1999) e LIEDKE e SILVA (1993), apontam para o crescimento da precarização nas relações de trabalho no geral e um grau mais acentuado dessa precarização sobre as condições de trabalho da mulher.

Uma das hipóteses dessa constatação é de que as mulheres estariam mais sujeitas a aceitar e desempenhar tarefas similares àquelas concebidas na 
esfera do paradigma da organização taylorista-fordista ${ }^{6}$ do trabalho, como sugerem CUNHA (1999) e HIRATA (1998). Há outros fatores relacionados às novas bases materiais de produção e às relações sociais e produtivas delas decorrentes, bem como às novas categorias que emergem desse processo, como a flexibilização produtiva e as implicações sobre os atributos da força de trabalho exigidos por ela.

Ao longo do quase centenário emprego do modelo taylorista-fordista de organização da produção, verifica-se a desvantagem que a mulher vem enfrentando em termos da hierarquização na divisão técnica do trabalho e, como decorrência desta, da defasagem salarial em relação aos homens. Esse fator é constatado inclusive em casos relacionados à ocupação da mesma função para o mesmo sexo.

$\mathrm{ABRAMO}^{7}$ apud CUNHA (1999) destaca, também, além das condições já apresentadas, uma continuidade das trajetórias laborais femininas. A mulher desempenha, em muitos casos, uma dupla jornada de trabalho, por conta dos afazeres domésticos: em uma parte de seu dia é operária e em outra é donade-casa, conforme apontado por WHITAKER:

Quanto à mulher, na sociedade moderna oscila entre o lar e a profissão. Milhões de mulheres ainda são prisioneiras do lar, porém, há que se reconhecer, milhões se libertaram. Não totalmente, é claro: já que não se resolveu, para a grande maioria, o dilema do cotidiano: conciliar o cuidado dos filhos, as tarefas domésticas e o mundo do trabalho fora de casa. Para a grande maioria, a profissão fica em segundo plano. E não se pode culpá-las. São responsáveis pelo funcionamento do lar e, no caso brasileiro, a sociedade não lhes oferece alternativas que permitam ao lar funcionar normalmente sem que para isso ela precise se esgotar de tanto trabalhar (WHITAKER, 1988, p. 13).

Esse cenário se acentua ainda mais com a questão da maternidade, onde ela fica sobrecarregada, tendo que conciliar o turno de trabalho, as tarefas domésticas e o acompanhamento dos filhos. Isso mostra que as mudanças nos processos de trabalho, decorrentes do avanço tecnológico, não atingem a todos os trabalhadores com a mesma intensidade, implicando na manutenção da divisão sexual do trabalho .

A divisão sexual do trabalho está determinada, de acordo com ENGELS (1984), à constituição dos modos de produção classistas. Desde quando se constituiu a propriedade privada para uma classe e outra classe foi destituída da mesma, e logo em seguida o Estado como expressão da classe dos proprietários, ou daqueles que controlam a propriedade privada, a mulher tornou-se sujeita à divisão sexual do trabalho ${ }^{8}$.

6 A denominação taylorista-fordista está associada aos nomes de F. Taylor e Henry Ford, respectivamente. É comum na literatura conceber-se o fordismo "como desenvolvimento do taylorismo". (MORAES NETO, 1986, p. 229)

7 ABRAMO, Laís. Sociologia do Trabalho na América Latina: novos paradigmas produtivos, relações de trabalho e relações de gênero. In: Reestructuración productiva, cambio tecnológico, género y sindicalismo en América Latina. Porto Rico: Carlos Alá Santiago e Elsa P. Larrinaga Editores, 1996.

8 A noção de divisão sexual do trabalho adotada no desenvolvimento deste estudo foi tomada a partir da Sociologia do Trabalho francesa, na esfera do Grupo de Estudos sobre a Divisão Social e Sexual do Trabalho - GEDISST, do Centro Nacional da Pesquisa Científica, da França. (HIRATA, 1998). 
A divisão sexual do trabalho, trata-se, portanto, de um fenômeno de contradição de classes, mas que não pode ser visto exclusivamente sob este ângulo. Caracteriza-se fundamentalmente como uma dimensão intraclasses, envolvendo o estudo não só da contradição entre o capital e o trabalho, mas da forma como se constrói a relação de gênero envolvendo a situação do homem operário e da mulher operária, marcados por essa contradição.

\subsection{A IDENTIDADE DOS TRABALHADORES(AS) - ATORES DA PESQUISA}

a classe que dispõe dos meios de produção material dispõe igualmente dos meios de produção intelectual, de tal modo que o pensamento daqueles a quem são recusados os meios de produção intelectual está submetido igualmente à classe dominante. Os pensamentos dominantes são apenas a expressão ideal das relações materiais dominantes concebidas sob a forma de idéias do seu domínio. Os indivíduos que constituem a classe dominante possuem entre outras coisas uma consciência, e é em conseqüência disso que pensam; na medida em que dominam enquanto classe e determinam uma época histórica em toda a sua extensão, é lógico que esses indivíduos dominem em todos os sentidos, que tenham, entre outras, uma posição dominante como seres pensantes, como produtores de idéias, que regulamentem a produção e a distribuição dos pensamentos da sua época; as suas idéias são, portanto, as idéias dominantes da sua época (MARX e ENGELS, 1980, p. 56).

Com base nesse entendimento são analisadas as identidades dos trabalhadores, mulheres e homens, a partir dos conteúdos de suas falas em resposta ao instrumento aplicado nesta pesquisa. A esse respeito constatou-se que a percepção que os trabalhadores têm de si e de seus pares, dos processos de trabalho e do conteúdo do trabalho que realizam está marcada pela condição de classe determinada a partir da posição que ocupam nas relações de trabalho capitalista, de modo geral, e na linha de produção da Empresa pesquisada, em particular.

Nesse contexto deve-se levar em conta que há várias posições ocupadas por diferentes categorias de trabalhadores no seio da classe operária, constituindo-se na divisão técnica dos trabalhos. Assim temos pertencentes à mesma classe: engenheiros, técnicos, supervisores, operadores, auxiliares, etc., segundo as características dos processos produtivos. Além desses ofícios ocorre a divisão de gênero, étnica, etária, dentre outras, podendo estar ocupando as mesmas posições, na linha de montagem, ou outras posições. No caso específico deste trabalho as preocupações estão centradas na identificação que os trabalhadores e as trabalhadoras têm de si e de seus pares, do conteúdo e do processo de trabalho.

A fala dos mesmos teve como eixo balizador a descrição sobre o que eles fazem no dia de trabalho. Nessa descrição os trabalhadores relataram o cotidiano dos processos de trabalho a que estão inseridos, a partir do que pode ou não ser executado em suas funções, como falou o entrevistado aqui denominado Alberto, do sexo masculino, Auxiliar de produção no setor de Injeção, empregado há 9 meses na Empresa, afirmando que já aprendeu muito sobre o trabalho. Diz esse trabalhador: 
cuido de 2 máquinas e às vezes 3 . O meu serviço é pegar as peças que saem das máquinas, conferir, embalar e liberá-las. Aqui eles têm um tipo de papel que eles chamam de planilha ${ }^{9}$, que você vai marcando o que produziu e vai embalando e vai liberando. Não pode demorar e nem misturar as coisas das máquinas, senão dá problema. Tem que ser rápido. O pessoal aqui é legal. (Alberto, 27 anos, Auxiliar de produção, setor de Injeção)

De acordo com esse mesmo entrevistado o serviço se torna mais apurado na hora da refeição, durante o seu turno, quando um auxiliar sai para jantar/almoço e "você fica com mais serviço".

Verifica-se que os processos de trabalho são entendidos não como um todo, como poderia ser concebido no bojo da chamada produção flexível, mas como algo pré-estabelecido, rígido e estandardizado ao modo da produção fordista, como pode-se depreender das próprias afirmações "eu cuido das máquinas"; "meu serviço mesmo é pegar as peças que saem das máquinas"; "não pode demorar"; e "tem que ser rápido".

Do mesmo modo a referência ao pessoal com os quais trabalha "o pessoal aqui é legal" expressa uma condição genérica acerca dos seus pares, sejam eles de níveis hierarquicamente abaixo ou acima na cadeia de produção dentro da Empresa. Verifica-se que o entendimento sobre os processos de trabalho e o conteúdo do trabalho, desse trabalhador, expressa uma condição intelectual submetida, tal qual foi concebida por Marx e Engels, acima referida, fruto de uma condição de subordinação a que está sujeito pelas bases materiais de produção.

O entrevistado, aqui chamado André, trabalha no setor de Injeção, há 4 anos, como Auxiliar de produção. Ele aponta em sua fala a noção de senso comum, expressando as visões binárias relacionadas à masculinidade e feminilidade, com relação a homens e mulheres desempenhando a mesma função da mesma maneira:

Homens e mulheres não fazem as tarefas da mesma maneira. Porque os homens já estão mais acostumados com o serviço. A mulher fica mais em casa. Nós homens estamos acostumados com o serviço 'pesado'. A mulher é mais delicada e não dá conta. (grifo nosso) (André, 33 anos, Auxiliar de produção, setor de Injeção).

Almeja o "tão sonhado" cargo de Operador de máquinas e diz estar se preparando para isso "estou fazendo o curso de Operador de $1^{\text {a }}$ linha no SENAI, para, se Deus quiser, passar para Operador".

A entrevistada Aurora trabalha como Auxiliar de produção há 2 anos nessa função, no setor de Impressão. Iniciou suas atividades na Empresa como Auxiliar de serviços gerais, onde fez, por 3 anos, a limpeza dos escritórios

9 Planilha, segundo o Supervisor entrevistado, é uma ficha interna na qual são apontadas as quantidades de produtos produzidos, com códigos, horários, número da máquina, nome do Operador e Auxiliar que embalou, data, enfim, todos os dados do produto para acompanhamento da produção da máquina, do turno e do setor. Esses dados são comparados com outros já previamente fornecidos pela área de PCP (Planejamento e Controle da Produção) com a programação do lote a ser produzido, conforme o pedido do cliente. 
administrativos. Por meio de recrutamento interno foi trabalhar na linha de produção. Evidencia, em sua fala, a submissão por parte das trabalhadoras em relação aos colegas homens, quando diz que

o Oto, Operador das máquinas, nos ensina e ajuda quando apura. Mas o serviço dele é mais apurado. E nós não podemos ajudá-lo porque seu serviço é mais difícil. (...) O trabalho sempre sai bem feito porque depende mais do Oto do que de nós, Auxiliares. Ele mesmo fala que em nosso serviço não é preciso pensar. (Aurora, 38 anos, Auxiliar de produção, setor de Impressão)

Expressa, também, a carência de treinamento adequado para ascensão à função de Operadora de máquina quando fala que "nós não podemos ajudar o Operador porque não sabemos mexer no computador das máquinas". Reforça o modo de trabalho repetitivo, no modelo taylorista-fordista, quando relata que seu trabalho é "só colocar e retirar frentes das gavetas dos freezers para imprimir os desenhos. Faço isso o dia todo".

A entrevistada, aqui denominada Adriana, trabalha no setor de Impressão há 2 anos, como Auxiliar de produção. É colega de turno de Aurora e reforça a condição de trabalho repetitivo. Ela relata que gosta desse trabalho repetitivo porque "não faz sujeira e a gente não mexe com coisa perigosa". Teme, no entanto, o incremento de novas tecnologias quando diz que "dizem que essa sessão vai acabar porque vai ter máquina que já vai fazer isso direto".

A entrevistada Arabela é Auxiliar de produção, no setor de Injeção e trabalha na Empresa há 8 meses. Trabalhava anteriormente como Panfleteira e compara sua antiga rotina na rua com seu trabalho dentro de uma empresa, hoje.

Aqui já começa tudo muito rápido porque a máquina está ligada e funcionando. Mas eu estou acostumada a trabalhar rápido, porque eu trabalhava na rua. Aqui eles regulam a gente. Olham tudo o que fazemos. (...) Mas eu mesma agradeço a Deus por esse emprego, porque é menos arriscado que trabalhar na rua. (Arabela, 25 anos, Auxiliar de produção, setor de Injeção)

Expressa o cuidado com o acabamento perfeito das peças e demonstra conhecer o processo do trabalho como um todo: "eu trabalho com acabamento nas tampas das gavetas. Só que não fica pronto aqui. Ainda vai para a Impressão, para estampar o desenho de cada uma. Não pode ter nenhum defeito, senão eles devolvem".

Ana é a entrevistada que trabalha há 3 anos como Auxiliar de produção no setor de Injeção. Reflete uma indignação acerca da compreensão que expressa em relação ao não reconhecimento do trabalho feminino. Uma posição de subalternidade que está imposta à mulher dentro da Empresa, mesmo em relação ao comando da mesma, como com os colegas do setor de trabalho:

Eu chego no serviço, bato o ponto e guardo minhas coisas no armário, vou para o setor e para a máquina onde trabalho. Pego as peças que caem da máquina: dou o acabamento, separo as com defeito grave e embalo as outras, conforme a planilha. Essa planilha diz o quanto se põe na caixa, qual a posição, tudo. Depois que a caixa está completa, cola-se a etiqueta de liberação - que serve para identificar o que foi posto na caixa - empilha-se junto com as outras de mesmo lote para que seja levada ao almoxarifado. É um trabalho que cansa, porque é sempre a mesma coisa. Eu já faço isso há 3 anos. Acabei o $2^{\circ}$ grau agora. Trabalho muito: aqui na Empresa, estudo, trabalho em casa e ainda tenho 2 filhos. 
Estou esperando uma promoção que me prometeram. Não sei para onde, porque já cheguei no limite como Auxiliar III. Mas sei que para Operador eles não me promovem. Não tem mulher operadora. Acho que eles imaginam que mulher não pensa, que não é capaz, que vai errar tudo e que só serve para limpar as coisas. Eu mesma opero máquina quando precisa. Mas eles não me reconhecem como Operadora. E duro, mas é verdade. (Ana, 28 anos, Auxiliar de produção, setor de Injeção)

A entrevistada, aqui denominada Andréia, trabalha no setor de Impressão, como Auxiliar de produção e está na Empresa há 2 anos. Trabalha no turno da madrugada, das 22 horas às 6 horas da manhã. Vem para o trabalho com o marido, funcionário do setor de Manutenção. Expressa o pouco reconhecimento dado à mulher que desempenha serviços domésticos quando diz que "eu acho que o serviço aqui é bom. Melhor do que em casa, onde você trabalha muito e não ganha nada". Reforça a condição de trabalho repetitivo e demonstra sua preocupação numa condição de gravidez, reafirmando a posição da Empresa em relação a essa situação, conforme relatado pela entrevistada da área de $\mathrm{RH}$ :

Eu não tenho filhos, mas sei que quando ficar grávida não vou mais poder trabalhar assim. Imagine você saindo da fábrica, que é quente, no frio da madrugada. Não dá. E eu também não tenho com quem deixar o nenê a noite toda. E eles aqui não gostam de mulher grávida. (Andréia, 23 anos, Auxiliar de produção, setor de Impressão)

Amália é a entrevistada que está na Empresa há 1 ano e 2 meses e trabalha como Auxiliar de produção no setor de Injeção. Lamenta a condição de trabalho repetitivo, porém necessário ao sustento da família, uma vez que é a única fonte de renda que possuem: "o trabalho é meio chato porque é sempre igual. Mas é bom trabalhar aqui porque meu marido está desempregado e já recebeu todo o seguro-desemprego. Aí fica apertado". Expressa, também, a impossibilidade em participar dos cursos e treinamentos oferecidos pela Empresa, uma vez que ocorrem fora do horário de expediente e sem hora-extra remunerada.

Eu já fiz mais ou menos uns 5 cursos aqui. Mas só os que eram obrigatórios. Queria fazer mais, mas o ruim é que tem que fazer fora do expediente e eles não pagam hora-extra. Eu tenho uma menina pequena e meu marido tem que procurar emprego. Aí não dá. (Amália, 23 anos, Auxiliar de produção, setor de Injeção)

A entrevistada, aqui denominada Augusta, é Auxiliar de produção há 2 anos, no setor de Injeção. Ela afirma que sua função pode ser desenvolvida por homens e mulheres da mesma maneira:

Eu limpo sempre a bancada, acho que a mulher cuida mais das coisas. Tem homem que não limpa. Não sei como consegue trabalhar na sujeira. (...) Na hora do almoço eu cuido de 3 máquinas, no lugar do Operador. Chamo o abastecedor $^{10}$, só não calibro, mas abro, puxo a peça e desengato. Faço o mesmo serviço que o Operador, mas aqui não tem mulher com o cargo de Operadora. (Augusta, 28 anos, Auxiliar de produção, setor de Injeção) 
O entrevistado, aqui denominado Otacílio, do sexo masculino, Operador de máquina no setor de Impressão, empregado há 4 anos na Empresa, manifesta em sua fala a compreensão do que ocorreu em termos de substituição de um tipo de tecnologia física por outra. Ou seja, com a introdução da microeletrônica computadorizada no setor de "Estamparia", que passou a ser denominado de "Impressão", onde trabalha. Afirma esse trabalhador:

Antes nós éramos em 3 aqui. Fazem quase 2 anos que sou só eu, no meu turno. O meu trabalho é regular as máquinas, verificar os pedidos e programar as impressoras. Antes eram outras máquinas, tudo com clichê, que era uma espécie de carimbo de tinta nas peças. Hoje não. O desenho já vem no computador. Não tem erro de fórmula de cor, nem perigo de refugo por causa da tinta. A impressão é toda feita a laser. Você só programa a máquina e ela vai imprimindo as peças. O nome da seção antes era Estamparia, por causa do sistema antigo. É um dos setores que menos dá refugo aqui na firma, porque se a máquina for bem programada não tem erro. O que dá problema aqui é quando o auxiliar é novato, aí ele, até pegar o jeito, se bate. Mas eu sempre ajudo, colaboro, procuro ensinar. Eu mesmo já trabalho aqui faz tempo e já peguei o jeito. (Otacílio, 29 anos, Operador de máquina, setor de Impressão)

Como pode ser observado, a incorporação da inovação tecnológica na maquinaria gerou a redução de dois terços da força de trabalho como documentou o operário "antes nós éramos em 3 aqui. Faz quase 2 anos que sou só eu".

Embora ele mesmo diga que o seu trabalho é "regular as máquinas, verificar os pedidos e programar as impressoras", diferente do que acontecia antes, em que tudo ocorria com um "clichê", ou seja, "uma espécie de carimbo" nas peças, constata-se a permanência de um tipo de trabalho ainda de modo heterogerido, quando ele afirma que "o desenho já vem no computador", não havendo "perigo de refugo". Esse entendimento da heterogestão, existente em associação ao processo de inovação tecnológica na produção, pode confirmar o que MACHADO (1994) aponta como "a nova modalidade do trabalho morto", representado pelo software. Trata-se, portanto, de processos de trabalho cujo aprendizado do conteúdo restringe-se ao "pegar o jeito". A visão desse trabalhador acerca do trabalho da mulher no seu setor reafirma a noção do senso comum, segundo o qual a mulher é "mais caprichosa e presta mais atenção". A diferença que ele aponta associa essa visão sobre a mulher com a capacidade da força física superior atribuída ao homem. Nesse sentido acaba exprimindo parte do pensamento dominante e, como tal, conservador. Ou seja, repete a noção dicotômica das "hierarquias estereotipantes" na definição da relação entre homem e mulher, como caracterizou YANNOULAS (2001, p. 71).

Odilon é o entrevistado do sexo masculino, que está trabalhando há 3 anos na Empresa como Operador de máquina no setor de Impressão, afirmou, respondendo sobre o que faz no seu dia de trabalho, que:

10 Segundo o Supervisor entrevistado, abastecedor é o operário responsável pelo abastecimento de matéria-prima nas máquinas, para a fabricação das peças. É, também, quem supre a área com caixas de papelão para a embalagem dos produtos. 
Eu chego no serviço e vejo nas planilhas os pedidos. Vejo os saldos dos lotes e continuo o trabalho feito pelo operador do turno anterior. Quando muda o lote ou a máquina descalibra, aí então eu reprogramo o pedido. À noite é muito diferente que de dia. Todo mundo se ajuda. Eu mesmo viro auxiliar. Embalo, libero, essas coisas. É menos gente trabalhando, então todo mundo se ajuda. A Impressão é vista como o "filé" da fábrica. Todo mundo acha que é um trabalho fácil demais. Mas eu sempre digo que é preciso fazer as coisas direito, com cuidado para não errar. Aqui é um setor igual aos outros. Tem meta para cumprir e lote para atender. O que muda é que a máquina faz a maior parte do serviço pesado. Qualquer um pode ser operador aqui, desde que saiba como lidar com as máquinas. Para isso é preciso fazer curso. (Odilon, 31 anos, Operador de máquina, setor de Impressão)

Da mesma forma que foi observado na fala do entrevistado anterior, percebe-se a manutenção de um tipo de trabalho concebido a partir do modelo de gestão externa, quando ele se refere à subordinação do seu trabalho aos pedidos das planilhas e às metas e os lotes para serem cumpridos. Constatase, também, que embora o seu setor seja considerado como o "filé da fábrica", numa alusão de que se trata de um bom setor de trabalho em comparação com os demais, não há uma alta complexidade no conteúdo do trabalho; pelo contrário, observa-se a existência de um tipo de trabalho simples quando ele afirma que "qualquer um pode ser operador", exigindo-se apenas "que é preciso fazer as coisas direito e com cuidado para não errar".

O entrevistado, aqui denominado Oto, do sexo masculino, Operador de máquina no setor de Injeção, trabalhando há 5 anos na Empresa, afirma que possui 11 anos de experiência:

Cada vez tem menos gente trabalhando na fábrica. É só máquina mesmo. E sempre querem que você produza mais e mais. Eu sou operador. Tem que ter muita responsabilidade e pensar rápido porque a produção não pode parar. Cada vez mais você tem que fazer mais coisa, por exemplo: antes quando a máquina parava a gente chamava a manutenção. Agora a gente tem as ferramentas básicas e tenta resolver. A operação de uma máquina injetora é simples. 0 abastecedor abastece a máquina com a matéria-prima granulada ${ }^{11}$, com a fórmula do produto, que o PCP manda. O operador precisa calibrar a máquina e conferir: a velocidade, a pressão, a lubrificação e principalmente a temperatura da máquina, para que o produto não saia com defeito. Antes, a gente cuidava de 1 máquina e ganhava um tanto. Hoje a gente ganha o mesmo e cuida de às vezes 3 máquinas ao mesmo tempo. Você tem que ter responsabilidade e rapidez e principalmente saber o que os caras querem. Aqui eu trabalho quieto. Eles não gostam de quem vai nas reuniões do Sindicato. Eu vou, quero ver os meus direitos. Mas aqui eles marcam. Eles gostam do cara certinho, que não atrasa. (Oto, 28 anos, Operador de máquina, setor de Injeção)

O discurso desse trabalhador expressa um nível de compreensão mais amplo sobre o processo de mudanças dentro da Empresa, envolvendo tanto os aspectos das tecnologias físicas, quanto organizacionais. Acerca da primeira, ele se refere à substituição das pessoas pelas máquinas. Quanto à segunda, fica evidente as atribuições multifuncionais que executa. Associando esses dois

11 Segundo o Supervisor entrevistado, a matéria-prima granulada a que se refere o trabalhador é plástica, denominada polipropileno. 
tipos de tecnologias, exprime-se a tecnologia de processos, tal qual definida por FARIA (1997), cujas conseqüências para a vida do trabalhador são várias, podendo ser destacadas a dispensa de trabalho vivo e o aumento de trabalho morto, o que já teria sido acusado por Marx, em O Capital, na análise crítica que procedeu sobre o desenvolvimento dos processos de produção no capitalismo. Disso decorre o aumento do desemprego na atual fase do capitalismo no Brasil e em termos mundiais.

Para FARIA (1997, p. 29),

tecnologia de processo compreende as técnicas e o uso de técnicas que interferem no processo de trabalho/produção, de maneira a modificá-lo, organizálo, racionalizá-lo, sejam tais técnicas de origem física (máquinas, peças e componentes), sejam de origem gerencial. A fibra ótica e os novos materiais cerâmicos, desta forma, são tecnologias de produto. Entretanto, quando utilizadas para viabilizar, facilitar ou melhorar a produção de outras mercadorias, passam a fazer parte do processo produtivo e, neste sentido - com este uso -, são tecnologias de processo.

Já a tecnologia de gestão, para o mesmo autor, é definida como:

o conjunto de técnicas, instrumentos ou estratégias utilizados pelos gestores gerentes, administradores, etc. - para controlar o processo de produção em geral, e de trabalho em particular, de maneira a otimizar os recursos nele empregados, pondo em movimento a força de trabalho capaz de promover a geração de excedentes apropriáveis de forma privada ou coletiva (social) (Ibid., p. 29-30).

Também o aumento da fadiga do trabalho fica evidente quando ele afirma que "antes a gente cuidava de 1 máquina e ganhava um tanto. Hoje a gente ganha o mesmo e cuida de às vezes 3 máquinas ao mesmo tempo". A esse processo pode-se atribuir o que MACHADO (1994) denominou de "mais-valia extraordinária", referindo-se ao aumento da produtividade do trabalhador, com o uso de novas tecnologias. Essa denominação de Machado, no entanto, nada mais é do que a constituição da "mais-valia relativa", concebida por Marx, na análise que fez sobre o incremento tecnológico na maquinaria pelo capitalista.

Isso não quer dizer que o discurso desse trabalhador esteja concebido teoricamente da forma como MARX (1994), FARIA (1997) e MACHADO (1994) elaboraram, mas no relato empírico que fez sobre a realidade do trabalho que executa, na qual podem ser encontrados os aportes práxicos desenvolvidos por aqueles autores.

Evidencia-se, ainda, na fala desse trabalhador, Oto, manifestações tanto de adesão quanto de resistência. No plano da adesão podem ser constatadas as formas com as quais ele se vincula às formas e ao conteúdo do trabalho, seguindo as definições da Empresa. Como resistência fica explícita a maneira como ele revela a sua participação no Sindicato e a estratégia de sobrevivência que utiliza dentro da Empresa, ao afirmar "aqui eu trabalho quieto. Eles não gostam de quem vai nas reuniões do Sindicato. Eu vou, quero ver os meus direitos".

Com relação ao trabalho da mulher na Empresa esse trabalhador confirma, sem identificar as causas apontadas pela representante de $\mathrm{RH}$, analisadas no Item anterior, a resistência em contratar mulheres para o nível 
operacional, afirmando que "a Empresa tem preconceito" não dando chance para as mulheres. Sobre a diferença entre o trabalho dos homens e o trabalho das mulheres, Oto afirma:

\begin{abstract}
Eu sou uma pessoa que incentiva muito as mulheres aqui. Na minha opinião tinha que ter mulheres operando máquina. Mas a Empresa tem preconceito, não dá chance mesmo. Eu já falei isso nas reuniões aqui e não adianta nada. Todo mundo concorda que as 'meninas' dão um acabamento melhor e mais rápido. Elas percebem a falha mais rápido, assim podiam muito bem operar a máquina. Mas não adianta que a cabeça dos homens aqui não muda. Quando eu trabalhava em outra firma, há quase 10 anos, mulher nem podia trabalhar à noite. Nunca achei isso certo. (grifo nosso) (Oto, 28 anos, Operador de máquina, setor de Injeção)
\end{abstract}

Em que pese o potencial crítico manifestado na fala desse trabalhador no que diz respeito ao "preconceito", por ele acusado, da Empresa contra a mulher, a sua base da resistência não apresenta elementos que pudessem indicar um nível de consciência de classe para si como concebida por MARX e ENGELS (1980).

$\mathrm{Na}$ entrevista do trabalhador aqui denominado Oberdan, Operador de máquina no setor de Injeção, há 4 anos, não ultrapassa os níveis de uma identidade pessoal. Limitou-se na sua fala a reafirmar os elementos de subordinação e adaptação às condições de trabalho dadas pela Empresa.

\footnotetext{
Eu procuro fazer o meu serviço direitinho como Jesus guia e orienta. Oro antes de entrar no setor e agradeço por mais um dia de trabalho. Vou até minhas máquinas e verifico a condição delas: qual parou, se tem defeito, se tem pedido. Aí é praticamente dar continuidade ao que já vem sendo feito. (Oberdan, 31 anos, Operador de máquina, setor de Injeção)
}

O entrevistado, aqui chamado Sandro, é Supervisor de produção há 5 anos e 3 meses no setor de Injeção. Na descrição do seu dia de trabalho fica evidente a existência dos processos de trabalho hierarquizados, fragmentados, inclusive no que diz respeito à divisão sexual do trabalho. A sua função caracteriza-se por verificar e acompanhar os processos de produção, a partir das planilhas de programação que são elaboradas, sem a participação dos Supervisores.

Possui, no entanto, o Supervisor, uma relativa autonomia para "mudar o pessoal de posição quando existe demanda maior em certa máquina"; "fazer as escalas de plantão" para trabalhar aos domingos e nas horas-extras e relacionar o seu setor com a área de Controle de Qualidade "para acompanhar os refugos e retrabalhos". Estas são as ações que ele descreve.

A relação que estabelece no âmbito das relações de poder e da hierarquia empresarial traduz uma identidade contraditória entre exercer-se profissionalmente acima dos trabalhadores que comanda e, ao mesmo tempo, estar na mesma linha de "risco" com eles, em face da lógica de acumulação da Empresa. A esse respeito ele diz

Eu acho que o Supervisor ainda é visto, pelos Operadores e Auxiliares, como 'patrão', como o dono da fábrica, pois eles vêm me pedir aumento de salário, férias e outras coisas. Eu tento colocar que sou tão funcionário quanto eles. $\mathrm{O}$ 
que muda é só o cargo. Mas eu também corro risco como eles. Faço reuniões quinzenais com os Operadores para discutir e avaliar os processos e buscar melhorias constantes neles. Eu sempre digo para eles que podem trabalhar 364 dias ao ano certo e 1 dia errado, que todos vão lembrar só desse dia errado. (grifo nosso). (Sandro, 36 anos, Supervisor de produção, setor de Injeção)

Confirmando a percepção dos Operadores de máquinas entrevistados, este Supervisor também vê que a Empresa não dá oportunidade para as mulheres pelo fato delas serem admitidas apenas na condição de Auxiliares de produção e não tê-las como Operadoras de máquinas. Sobre isso afirma que "nós não temos mulheres Operadoras de máquina, no entanto elas são mais caprichosas, mais atenciosas e mais responsáveis que os homens. Mas por uma questão de política interna elas não são Operadoras 'oficiais', porque quando é preciso, elas operam as máquinas".

A "política interna" da Empresa a que se referiu o Supervisor diz respeito à condição empregada pela área de $\mathrm{RH}$, para excluir a mulher na contratação para determinadas funções, quer porque ela procrie, quer porque ela assuma um conjunto de atribuições domésticas como responsabilidades pela escola, creche, e/ou tratamento de saúde dos filhos, ou resolver outros problemas domésticos, na divisão sexual do trabalho extra-empresa. Assim a Empresa, segundo a posição da entrevistada do $\mathrm{RH}$, estaria agindo de acordo com as diferenças de gênero dicotomizadas entre masculino/feminino, segundo os papéis cultural e social ideologicamente predominantes em nossa sociedade, segundo a qual "ao homem corresponderia o papel instrumental de provedor da família, enquanto à mulher o papel expressivo de responsabilidade pelo bem estar emocional da família" (CARVALHO, 2003, p. 16).

A divisão sexual do trabalho, nessa Empresa, estaria, deste modo, não só segregando a mulher em termos quantitativos (no complexo empresarial em Curitiba são 738 homens para 440 mulheres e, na unidade fabril pesquisada são 436 funcionários homens para 126 funcionárias mulheres), como em termos qualitativos, pois constatou-se que, no setor operacional de Injeção, as funções destinadas às mulheres são as mais simples e as mais rebaixadas no grau hierárquico, em que pese do ponto de vista essencialista da qualificação elas estejam capacitadas para o exercício da operação das máquinas.

A fala do Supervisor reafirma, por outro lado, além da noção binária, presente no senso comum, de que a mulher é mais caprichosa, atenciosa, responsável, etc., um novo sentido da qualificação real da mulher, ao afirmar que embora elas estejam designadas como Auxiliares e não como Operadoras "oficiais", elas operam as máquinas quando há necessidade, na ausência dos Operadores.

Ele admite a existência de uma condição de machismo entre os trabalhadores, homens e mulheres, manifestada por meio de brincadeiras e piadinhas, entre outras formas. Sobre o machismo que afirma existir ele atribui que o mesmo é fruto das condições de trabalho, expressando que:

Acho que é o tipo de trabalho que faz isso (machismo), porque os homens operam e as mulheres auxiliam na produção. (...) Pelo tipo de trabalho, os homens se acham superiores. Mas eu também acho que as mulheres aceitam isso. Há uma ou outra que às vezes vem falar mais forte, mas a maioria dá graças por estar empregada. (Sandro, 36 anos, Supervisor de produção, setor de Injeção) 
Esse Supervisor reconhece muito o trabalho feminino pois é viúvo e desempenha as funções de pai e mãe em sua casa, cuidando de seus dois filhos.

\section{CONSIDERAÇÕES FINAIS}

A realização desta pesquisa revelou que as novas formas de organização da produção, implicando tanto o uso de novas tecnologias físicas quanto organizacionais, longe de afirmar maiores oportunidades de inserção da mulher no emprego e no crescimento das funções dentro da Empresa, indicam um acentuado grau de precarização das condições de trabalho para a mulher, implicando em elevada situação de limites na absorção de sua força de trabalho pela Empresa, bem como a sua manutenção em funções subalternas na hierarquia da produção em relação aos homens.

Verificou-se uma situação de inferioridade da mulher operária nas funções estabelecidas pela produção, conforme foi constatada na opinião dos três segmentos investigados: a representante da Empresa, os homens operários e as mulheres operárias.

Para a representante do capital, as dificuldades da Empresa em contratar um número maior de mulheres ou de promovê-las a funções de maiores responsabilidades nos processos de trabalho, estão atreladas, principalmente, pelo que acusa como "absenteísmo", relacionado-o a uma maior possibilidade, em relação aos homens, de falta no trabalho por conta das responsabilidades que assumem da divisão sexual do trabalho, no cotidiano da vida familiar.

Averiguou-se, também, que há uma confirmação no cenário empírico investigado com o que se constatou na literatura, ou seja, uma crescente precarização das condições de trabalho da mulher, no bojo do desenvolvimento do paradigma flexível (ou toyotismo) de acumulação do capital, envolvendo pesquisas realizadas sobre o tema, permitindo-nos inferir que os estudos sobre a temática têm muito a percorrer, sobretudo no que diz respeito aos aspectos da feminização do trabalho. E desse modo caracterizando as formas e os conteúdos principais do tipo de trabalho destinado à mulher no bojo da reestruturação produtiva operada pelo capital na atualidade.

O ponto de vista dos homens operários expressa a natureza do trabalho que realizam, apontando que não vêem dificuldades para que as mulheres exerçam as mesmas funções que eles ocupam na produção. Observam, no entanto, que o impedimento delas para ocupar determinados postos de trabalho, como o caso de operação de máquinas, decorre de fatores de ordem gerencial. Constatou-se que esse é um fator que tem a sua origem nas relações de poder e de controle da produção pelo capital, que dita, em última instância, os destinos da divisão sexual dos processos de trabalho, segundo sua lógica de acumulação.

As mulheres operárias revelaram uma percepção sobre os processos de trabalho nos quais estão inseridas, manifestando claramente a forma preconceituosa como são tratadas dentro da Empresa. Para elas não há dificuldades no exercício da função de Operadoras de Máquinas, função que às vezes desempenham nos períodos de ausência nas máquinas dos colegas homens. O preconceito, portanto, tem a sua origem nas determinações do 
capital.

Em síntese, constatou-se que a percepção dos três segmentos investigados, traduz um cenário de discriminação da mulher trabalhadora, explorada pelo capital. A procriação é vista nesse contexto como um empecilho ao desenvolvimento da função, e o direito da mulher gestante à licençamaternidade, após dar à luz ao seu filho, é interpretado como um fator de queda da competitividade empresarial. Ou seja, o capital acima da vida.

\section{REFERÊNCIAS}

BRASIL. Constituição da República Federativa do Brasil. Brasília: Senado Federal, Centro Gráfico, 1988.

CARVALHO, Marília G. de. Relações de gênero e tecnologia: uma abordagem teórica. In: CARVALHO, Marília G. de. (Org.). Relações de Gênero e Tecnologia. Curitiba: CEFETPR, 2003.

CHIZZOTTI, Antonio. Pesquisa em ciências humanas e sociais. São Paulo: Cortez, 2000.

CUNHA, Maria Amália de A. Gênero no trabalho: desemprego, exclusão e precariedade. In: Trabalho \& Educação. Revista do NETE, 1999, nº 06.

ENGELS, Friedrich. A origem da família, da propriedade privada e do Estado. São Paulo: Global, 1984.

FARIA, José H. de. Tecnologia e processo de trabalho. Curitiba: UFPR, 1997.

HIRATA, Helena. Reestruturação produtiva, trabalho e relações de gênero. In: Gênero, Tecnologia e Trabalho: Revista Latino-americana de Estudos do Trabalho - Associação Latino-Americana de Sociologia do Trabalho. Rio de Janeiro: 1998, ano 4, nº 7, 1998.

Nova divisão sexual do trabalho? Um olhar voltado para a empresa e a sociedade. São Paulo: Boitempo, 2002.

LIEDKE, Elida R.; SILVA, Lorena H. Inovações na organização do processo de trabalho e relações de gênero. In: Educação \& Sociedade: Revista Quadrimestral de Ciência da Educação - Centro de Estudos de Educação e Sociedade CEDES. Campinas: Papirus, 1993.

MACHADO, Lucília R. de S. A educação e os desafios das novas tecnologias. In: FERRETTI, Celso J. et al (Orgs.). Novas tecnologias, trabalho e educação - um debate multidisciplinar. Petrópolis: Vozes, 1994.

MARX, Karl. O capital: a crise da economia política: livro 1. 14 a edição. Rio de Janeiro: Bertrand Brasil, 1994,

MARX, Karl e ENGELS, Friedrich. A ideologia alemã I. Portugal: Presença, 1980.

MORAES NETO, Benedito R. Maquinaria, taylorismo e fordismo: a reinvenção da manufatura. In: Revista Novos Rumos. São Paulo: Novos Rumos, 1986.

WHITAKER, Dulce. Mulher \& Homem: o mito da desigualdade. São Paulo: Moderna, 1988.

YANNOULAS, Silvia C. Notas para a integração do enfoque de gênero na educação profissional. In: VOGEL, Arno. (Org.). Trabalhando com a diversidade no PLANFOR: raça/cor, gênero e pessoas portadoras de necessidades especiais. São Paulo: UNESP/ Brasília: FLACSO do Brasil, 2001. 